\title{
Effect of high-fat diet-induced obesity on thyroid gland structure in female rats and the possible ameliorating effect of metformin therapy
}

\author{
S.M. El-Sayed, H.M. Ibrahim \\ Department of Anatomy and Embryology, Faculty of Medicine, Ain Shams University, Cairo, Egypt
}

[Received: 16 July 2019; Accepted: 18 August 2019]

Background: Obesity is known to induce a state of lipotoxicity that affects the different organs of the body. Metformin is an antidiabetic drug commonly used in obesity treatment. It was known to improve thyroid function and its regulating hormones. Structural changes in the thyroid gland associated with obesity have not been well investigated. So, the aim of the present study is to detect structural changes in thyroid gland induced by obesity and to investigate the possible protective role of metformin therapy.

Materials and methods: Thirty adult female albino rats were divided into three groups (10 rats each). Group I (control group), group II (rats fed with a high-fat diet), and group III (rats fed with a high-fat diet and treated with metformin therapy). After 12 weeks, rats from all groups were sacrificed. Blood samples were taken for measurement of lipid profile, thyroid stimulating hormone (TSH), free T3 and free T4. Thyroid glands were extracted and processed for histological and ultrastructural study. Morphometric measurements for the colloid area of thyroid follicles and height of the follicular cells were done.

Results: Group I displayed normal biochemical parameters and architecture of the thyroid gland. Group II revealed disordered lipid profile, high TSH, free T3 and T4. Microscopically, large thyroid follicles with excessive colloid accumulation and decreased follicular cells height were seen. Some follicular cells showed pyknotic nuclei, vacuolated cytoplasm and disrupted basement membrane with mast cell infiltration of the thyroid tissue. Ultrastructurally, group II follicular cells showed loss of apical microvilli, dense shrunken nuclei, dilated endoplasmic reticulum, swollen damaged mitochondria with large intracellular vacuoles and colloid droplets. In group III, the biochemical parameters and structure of thyroid follicles were improved, and they had a near-normal appearance.

Conclusions: Obesity induced by high-fat diet in female rats structurally and functionally changed the thyroid gland in a way that may explain hypothyroidism associated with obesity. These changes were improved by metformin therapy. (Folia Morphol 2020; 79, 3: 476-488)

Key words: thyroid gland structure, obesity, high-fat diet, metformin

Address for correspondence: Sayed Mostafa El-Sayed, Taibah University, Medina, Universities Road, PO Box: 344, Kingdom of Saudi Arabia, tel: 00966557592579, e-mail: drsayedanatomy@gmail.com 


\section{INTRODUCTION}

Nowadays, obesity is a major dilemma for all the health workers over the globe and becomes a leading cause of many diseases as cardiovascular diseases, diabetes, and cancer [31] with significant multiple endocrine systems affection [5], including thyroid dysfunction [8]. Obesity is characterised by secretion of diverse inflammatory cytokines from adipose tissue as tumour necrosis factor-alpha and interleukins 1 and 6 that reach the blood and lead to decreased iodide uptake by thyroid cells in rats and humans with secondary increase in thyroid stimulating hormone (TSH) level $[2,37]$.

Genetic and environmental factors play a role in the aetiology of obesity, and diet is one of the main environmental factors that contribute to this disease. Numerous researches on human have shown that increased fat consumption is associated with body weight gain which can lead to multiple metabolic diseases and obesity. Routinely, animal rodent models are valuable tools for studying obesity and its related disorders as they can rapidly gain weight when fed by high-fat diet (HFD) $[7,19]$.

The thyroid gland synthesizes thyroid hormones that play a crucial role in metabolism and in the development, differentiation, and maintenance of the skeletal, cardiovascular and nervous systems [45]. The production and secretion of the hormones by the thyroid gland are directly regulated by the hypothalamus-pituitary-thyroid axis [28]. The pituitary gland serves as a biosensor of thyroid hormone levels. It secretes TSH in blood according to the feedback of free thyroxine (FT4) and free triiodothyronine (FT3). Worldwide, thyroid diseases especially hypothyroidism have attained epidemic proportions although the causes for the enhanced prevalence of the thyroid disorders remain unclear [41].

Metformin is one of the commonly used antidiabetic drugs over many years [10]. Metformin could affect (TSH) levels without affecting thyroid hormones levels [16]. Also, it decreased thyroid volume and size of its nodules in patients with insulin resistance [4]. It was found to have a direct anti-proliferative action on the thyroid gland through inhibiting mammalian target of rapamycin (mTOR) activity [14]. Like surgery, metformin therapy in obese diabetic persons normalised high (TSH) levels [35]. Study of the histological changes of the thyroid gland with obesity was very limited up till now. So, the aim of the present study was to detect the structural changes of the thyroid gland in obese female rats and to evaluate the possible role of metformin therapy.

\section{MATERIALS AND METHODS}

\section{Animals}

Thirty adult female albino rats aged 5-7 months were selected for the current study, their weight was 150-180 g. This study was performed in the Medical Research Centre, Faculty of Medicine, Ain Shams University. For 7 days, the animals were maintained under strict sterile conditions with unrestricted access to food and water and 12/12 h light and dark cycle. All the procedures of the experiment were carried out according to the guide rules of the Committee of the Animal Research Ethics (CARE), Faculty of Medicine, Ain Shams University.

\section{Experimental design}

The rats were separated into three groups:

- group I (the control group; $\mathrm{n}=10$ ): rats in this group were nourished a standard chow diet for 12 weeks;

- group II (model of obesity; $\mathrm{n}=10$ ): rats in this group were nourished a HFD for 12 weeks for induction of obesity and received distilled water orally in the last 4 weeks of the study (weeks 9-12) [38];

- group III $(n=10)$ : rats in this group were nourished a HFD for 12 weeks and received metformin orally $(100 \mathrm{mg} / \mathrm{kg} /$ day) [47] in the last 4 weeks of the study (weeks 9-12).

Measurements of waist circumference and body weight of the rats were done weekly. After 12 weeks, anesthetisation of animals was done, blood samples were obtained by puncturing of the hearts and the sera were used for biochemical examinations and then they were sacrificed. The thyroid glands were extracted from all animals, washed in saline, and then prepared for histological study (light and electron microscopic study).

\section{Biochemical investigations \\ Serum lipid profile}

Estimation of serum concentrations of total cholesterol (TC) and triglyceride (TG) were done by the colorimetric method using commercial kits (Biolabo-France). High density lipoprotein (HDL)-cholesterol was assayed by ELISA kits (Bioassay Technology Laboratory, China) (Acikel et al., 2019 [1]), and low density lipoprotein (LDL)-cholesterol was measured using the Friedewald equation [34]. 


\section{Serum thyroid hormones}

Serum levels of FT3, FT4, total T3, and TSH were measured using a competitive electrochemiluminescence immunoassay on the Roche E Modular system (Roche Diagnostics, Indianapolis, IN).

\section{Diet}

Standard chow diet was purchased from Meladco for Animal Food, El-Obour, Egypt. It consisted of $20 \%$ protein, $4 \%$ fat, $70 \%$ carbohydrates, $3 \%$ fibres, $1 \%$ vitamins, and $2 \%$ mineral salts in the form of pellets.

The HFD was a blend of chow pellets (72.8\%), cholesterol white powder (Sigma-Aldrich Chemicals, Germany) (2\%), commercial lard liquid oil (25\%) and bile salts (Sigma-Aldrich Chemicals) brown powder $(0.2 \%)$. This mixture was formed every week forming pellets that were dried and kept in a fridge [38].

\section{Tissue preparation for histological study}

The thyroid glands of all rats were cut to small parts ( $3 \mathrm{~mm}$ thick) and fixed in a solution formed of $2.5 \%$ paraformaldehyde and $2.5 \%$ glutaraldehyde for 24 hours at $4^{\circ} \mathrm{C}$. Post-fixation was done in $1 \%$ osmium tetroxide and dehydration in rising grades of alcohol. Then the taken tissue pieces were dropped in two changes of propylene oxide to be finally fixed in epon. Semi-thin sections ( $1 \mu \mathrm{m}$ thickness) were prepared and stained with $1 \%$ toluidine blue and inspected with the light microscope. Then ultra-thin sections (60 $\mathrm{nm}$ thickness) were cut, mounted on copper grids and stained with uranyl acetate and lead citrate. The grids were then inspected with the transmission electron microscope (Seo-Russia) in Faculty of Science; Ain-Shams University, Cairo [36].

\section{Morphometric study}

Ten non-overlapping high-power fields $(\times 400)$ per each group, in the toluidine blue stained semithin slides were examined. The images of the three groups were taken by a Nikon microscope connected with Nikon camera. The follicular epithelial height and colloid area of thyroid follicles were measured in pixel and pixel [21] respectively using Digimizer software programme version 4.6.1.

\section{Statistical analysis}

The obtained data were evaluated using SPSS software version 20 (SPSS Inc. Chicago, USA). One-way ANOVA test was selected to compare between the follicular epithelial height and colloid area of thy- roid follicles in the different studied groups. Values gained were stated as means \pm standard deviation (SD) and differences with $p<0.05$ were considered to be statistically significant.

\section{RESULTS}

\section{Body weight and waist circumference}

There was progressively increasing weight gain in groups I and II over the 12 weeks of the study with a statistically significant higher weight gain in group II than group I. Group III displayed progressively increasing weight gain similar to group I till $8^{\text {th }}$ week of the study. Thereafter, there was abrupt marked decrease in body weight in group III rats (Fig. 1A). At the end of the experiment, group II had an extremely statistically significant higher weight gain than group I ( $p<0.0001$ ), meanwhile, group III had an extremely statistically significant lower weight gain than both groups I and II ( $<<0.0001)$ (Table 1, Fig. 1B).

\section{Lipid profile}

Serum concentrations of all lipids (TC, TG, HDL and LDL) were markedly increased in group II with an extremely statistically significant difference as compared to group I. Group III displayed reduction of serum concentrations of all lipids with an extremely statistically significant difference as compared to group II (Table 1, Fig. 1C).

\section{Hormonal profile}

Serum free T3 was diminished in group II with a statistically significant difference $(p=0.0305)$ as compared to group I, meanwhile, group III displayed a marked rise of free $\mathrm{T} 3$ with an extremely statistically significant difference as compared to group II. Serum free T4 was markedly reduced in group II with an extremely statistically significant difference $(p<0.0001)$ as compared to group I, meanwhile, there was a marked rise of free T4 in group III with an extremely statistically significant difference $(p<0.0001)$ as compared to group II. Serum TSH concentration was markedly increased in group II with an extremely statistically significant difference $(p<0.0001)$ as compared to group I, on the contrary, it was markedly reduced in group III with an extremely statistically significant difference $(p<0.0001)$ as compared to group II (Table 1, Fig. 1D).

\section{Light microscopy \\ Group I (control group)}

Thyroid gland revealed many thyroid follicles of variable size. Each follicle was lined by a single layer of 

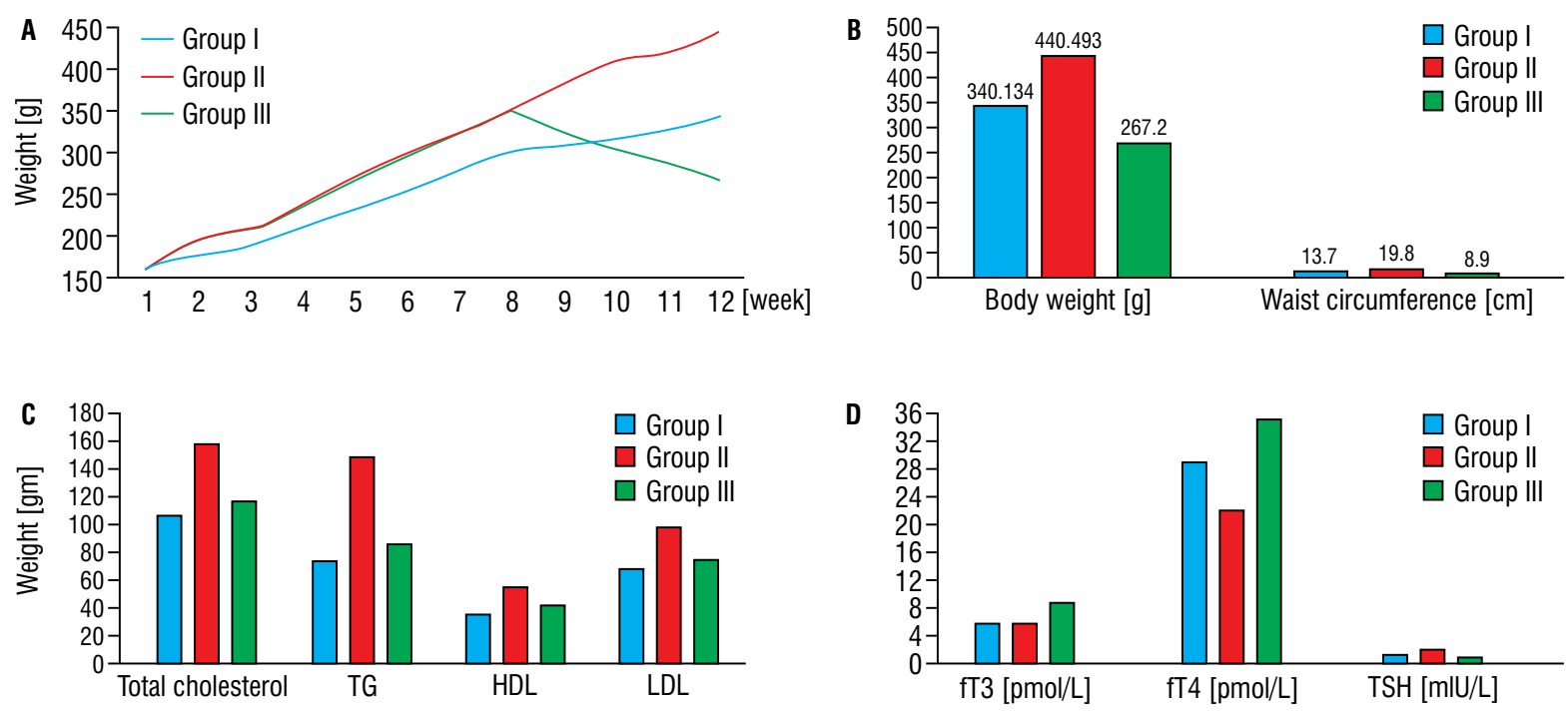

Figure 1. A histogram displaying; A. The body weight of the different groups along the study; B. The body weight and waist circumference of the different groups at the end of the study; $\mathbf{C}$. The lipid profile of the different groups at the end of the study; $\mathbf{D}$. The thyroid hormones levels of the different groups at the end of the study.

Table 1. General and biochemical parameters

\begin{tabular}{lccc}
\hline & Group I & Group II & Group III \\
\hline Body weight [g] & $340.13 \pm 2.16$ & $440.49 \pm 0.97^{*}$ & $267.2 \pm 0.62^{* *}$ \\
Waist circumference [cm] & $13.7 \pm 13.2$ & $19.8 \pm 20.01$ & $8.9 \pm 9.94$ \\
Serum cholesterol [mg/dL] & $107.58 \pm 2.97$ & $158.14 \pm 4.85^{*}$ & $115.65 \pm 6.78^{* *}$ \\
Serum triglyceride [mg/dL] & $74.84 \pm 2.91$ & $145.3 \pm 2.98^{*}$ & $83.27 \pm 3.1^{* *}$ \\
Serum HDL [mg/dL] & $35.29 \pm 2.71$ & $53.88 \pm 2.24^{*}$ & $40.78 \pm 1.83^{* *}$ \\
Serum LDL [mg/dL] & $68.54 \pm 2.40$ & $97.08 \pm 2.72^{*}$ & $74.2 \pm 2.29^{* *}$ \\
Free T3 [pmo//L] & $6.38 \pm 0.24$ & $6.15 \pm 0.21^{*}$ & $12.92 \pm 0.45^{* *}$ \\
Free T4 [pmo/L] & $37.33 \pm 0.32$ & $29.25 \pm 0.21^{*}$ & $43.4 \pm 0.32^{* *}$ \\
TSH [mlU/L] & $0.47 \pm 0.04$ & $1.18 \pm 0.07^{*}$ & $0.64 \pm 0.04^{* *}$ \\
\hline
\end{tabular}

All results are expressed as mean \pm standard deviation. P value $=$ probability of chance, $p<0.05$ is significant; ${ }^{*}$ indicates a significant difference $\left(^{*} p<0.05\right.$ vs. group I, ${ }^{* *} p<0.005$ vs. group II, ANOVA test).

cuboidal follicular cells with spherical vesicular nuclei, and a lumen filled with moderate amount of homogenous colloid (euthyroid appearance). The follicles were separated by capillary beds with flat endothelium. Normal parafollicular cells were encountered in the follicular cuboidal epithelium within the basement membrane and between follicles. They appeared as large cells with spherical vesicular nuclei and pale cytoplasm. Some inter-follicular cells were seen that may be tangentially cut follicles (Fig. 2A).

\section{Group II}

Thyroid gland of group II animals showed hypothyroid follicles of varying diameters, with a preponderance of large follicles (macro-follicles) exhibiting excessive amount of colloid. The follicular epithelial cells showed an apparent decrease in height and some of them were markedly flattened with flat and oval nuclei. The nuclei of some cells were also deeply stained, flat or shrunken i.e. pyknotic (Fig. 2B). The cytoplasm was vacuolated in some follicular cells, and the basement membrane was disrupted. Some parafollicular cells displayed pyknotic nuclei. There was a variation in the density of colloid between follicles and some follicles presented colloid vacuolation. The capillaries were compressed between the distended follicles and could be hardly seen. The inter-follicular connective tissue presented infiltration by mast cells (Fig. 2C). The mast cell infiltration involved also the loose connective tissue surrounding the thyroid gland (Fig. 2D). 

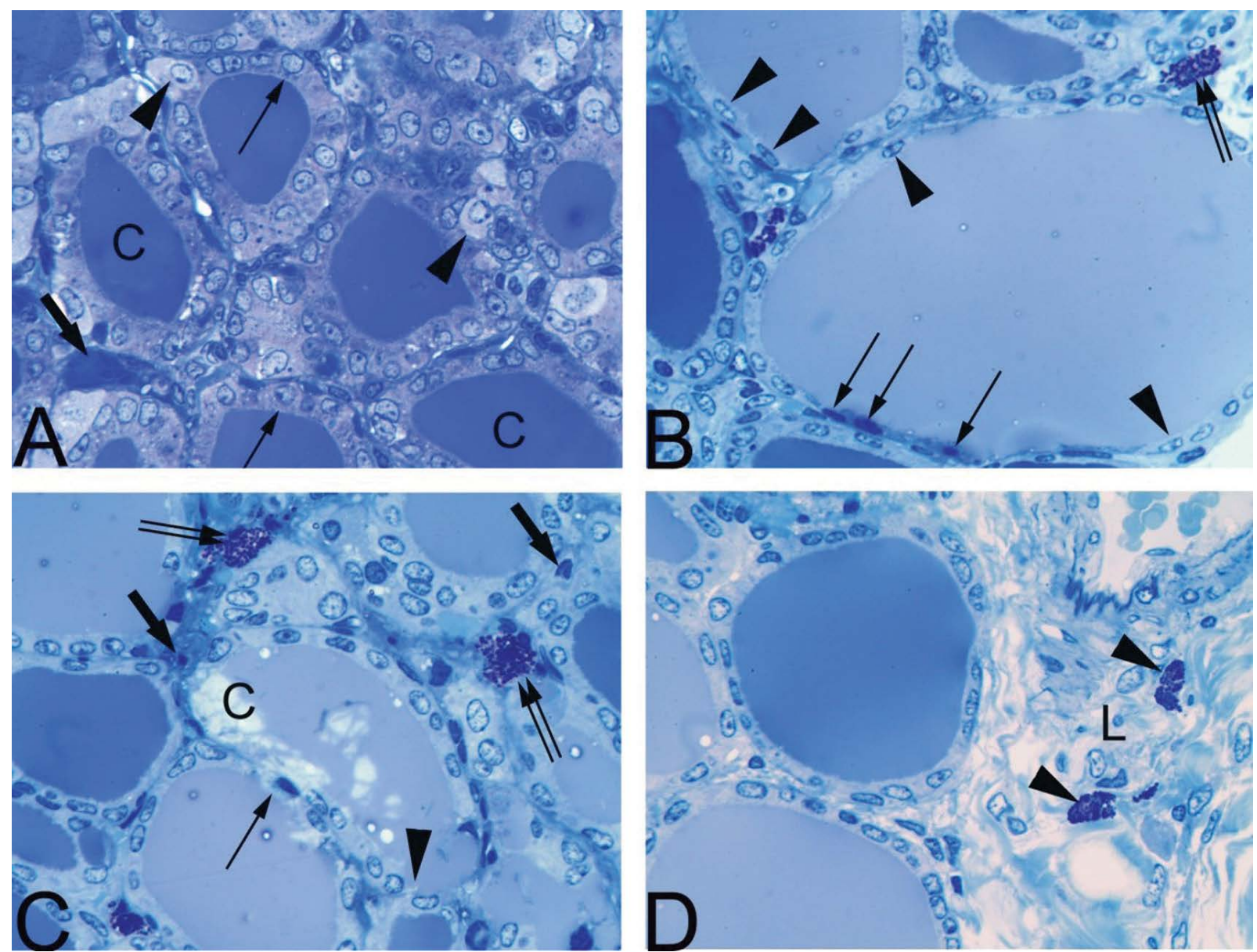

Figure 2. Photomicrographs of sections of the thyroid gland of; A. Control group (group I) displaying cuboidal follicular cells (arrow), parafollicular cells (arrow head), colloid (C), and capillary bed (thick arrow); B, C, D. Group II; B. Displaying excessive amount of colloid, flattened follicular cells (arrow head), pyknotic nuclei (arrow), and mast cells infiltration (double arrow); C. Displaying vacuolated cytoplasm in some follicular cells (arrow), disrupted basement membrane (arrow head), and parafollicular cells with pyknotic nuclei (thick arrow). There is variation in the density of colloid between follicles and also vacuolated colloid (C). Mast cells infiltration is seen (double arrow); D. Displaying mast cells infiltration (arrow head) in the loose connective tissue surrounding the thyroid gland (L). Toluidine blue $\times 400$.
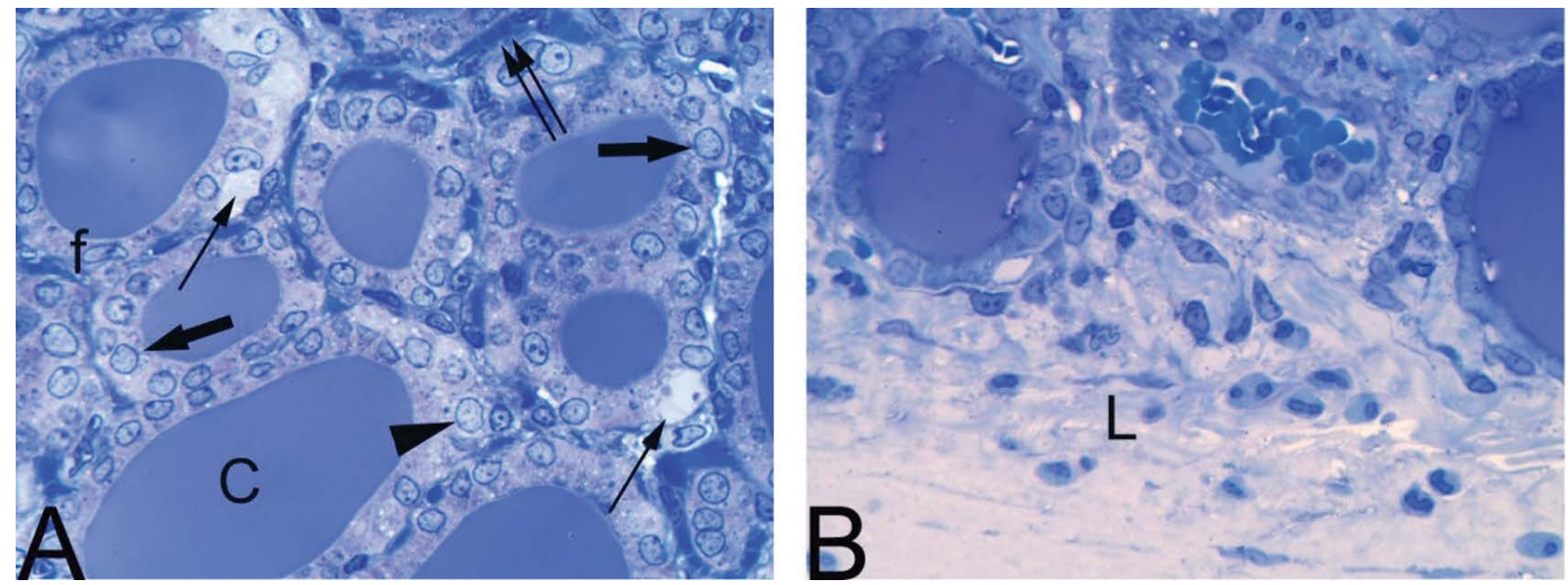

Figure 3. Photomicrographs of sections of the thyroid gland of group III; A. displaying a near-normal follicular structure with cuboidal follicular cells having rounded vesicular nuclei (thick arrow) and some cells are still flat with oval vesicular nuclei (f). Few cells still show vacuolated cytoplasm (arrow). The colloid (C) is moderate in amount. Parafollicular cells (arrow head) mostly exhibit a near-normal structure with large rounded vesicular nuclei. Capillary beds are seen in between the follicles (double arrow); B. Displaying no mast cells infiltration between the follicles and in the loose connective tissue (L) surrounding the thyroid gland. Toluidine blue $\times 400$. 

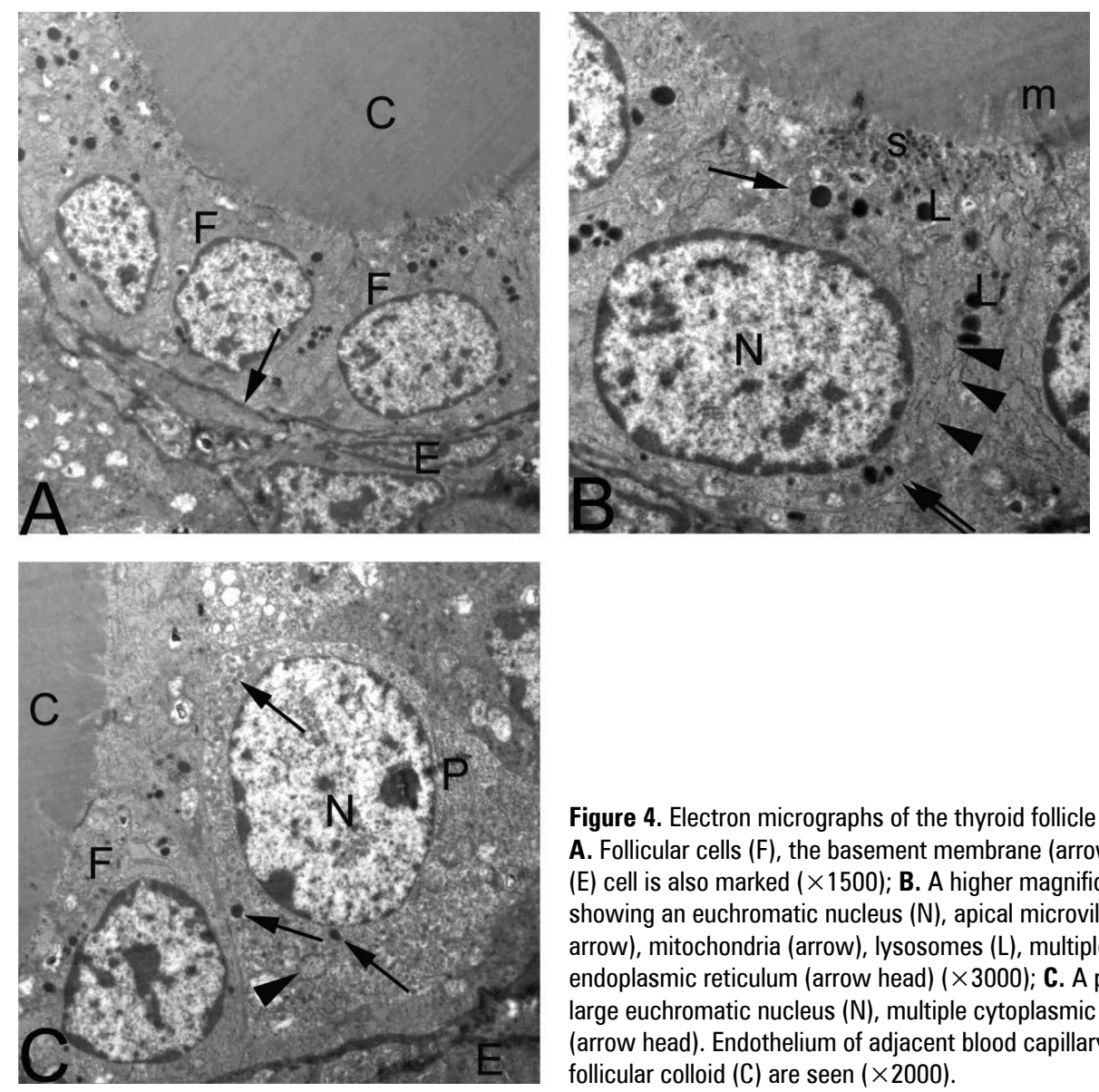

Figure 4. Electron micrographs of the thyroid follicle of group I (control) showing; A. Follicular cells (F), the basement membrane (arrow) and the colloid (C). Endothelial (E) cell is also marked $(\times 1500)$; B. A higher magnification of the previous micrograph showing an euchromatic nucleus (N), apical microvilli (m), plasmalemma (double arrow), mitochondria (arrow), lysosomes (L), multiple secretory granules $(\mathrm{S})$ and endoplasmic reticulum (arrow head) $(\times 3000)$; C. A parafollicular cell $(P)$ is seen with large euchromatic nucleus (N), multiple cytoplasmic granules (arrow) and mitochondria (arrow head). Endothelium of adjacent blood capillary (E), a follicular cell (F), and the follicular colloid (C) are seen $(\times 2000)$.

\section{Group III}

Thyroid gland of metformin-treated animals (group III) showed a near-normal follicular structure. The follicular epithelial cells appeared cuboidal with spherical vesicular nuclei, but some cells were still flat with oval vesicular nuclei. The cytoplasm of few cells still showed vacuolations. The colloid was moderate in amount without vacuolation. Most of the parafollicular cells showed a near-normal structure with large spherical vesicular nuclei and pale cytoplasm. There was no variation in the density of colloid between follicles. The capillaries could be seen in-between the follicles (Fig. 3A). No mast cells infiltration could be observed in between the follicles and in the loose connective tissue surrounding the thyroid gland (Fig. 3B).

\section{Electron microscopy}

\section{Group I (control group)}

Light microscopic findings were confirmed by electron microscopy. Thyroid follicular cells of group I rats appeared normal, resting on the basement mem- brane with prominent plasmalemma, euchromatic nuclei and apical microvilli protruding into the follicular lumen. The cytoplasm revealed mitochondria, moderately dilated endoplasmic reticulum, secretory granules varying in size, lysosomes, and ribosomes. The endothelium of blood capillaries could be detected (Fig. 4A, B).

The parafollicular cells of group I rats showed large euchromatic nuclei, numerous variably sized cytoplasmic granules, clusters of ribosomes, and mitochondria. They were present mainly adjacent to blood capillaries (Fig. 4C).

\section{Group II}

Thyroid follicular cells of group II rats showed significantly decreased cell height and flat or oval nuclei. There was markedly huge amount of colloid in the follicular lumen. Moreover, some follicles showed blunt apical surface with loss of apical microvilli (Fig. 5A).

Some follicular cells showed irregular shrunken nuclei with dense chromatin, an apparent decrease in the number of ribosomes and secretory granules. Moreover, they demonstrated markedly dilated endoplasmic 

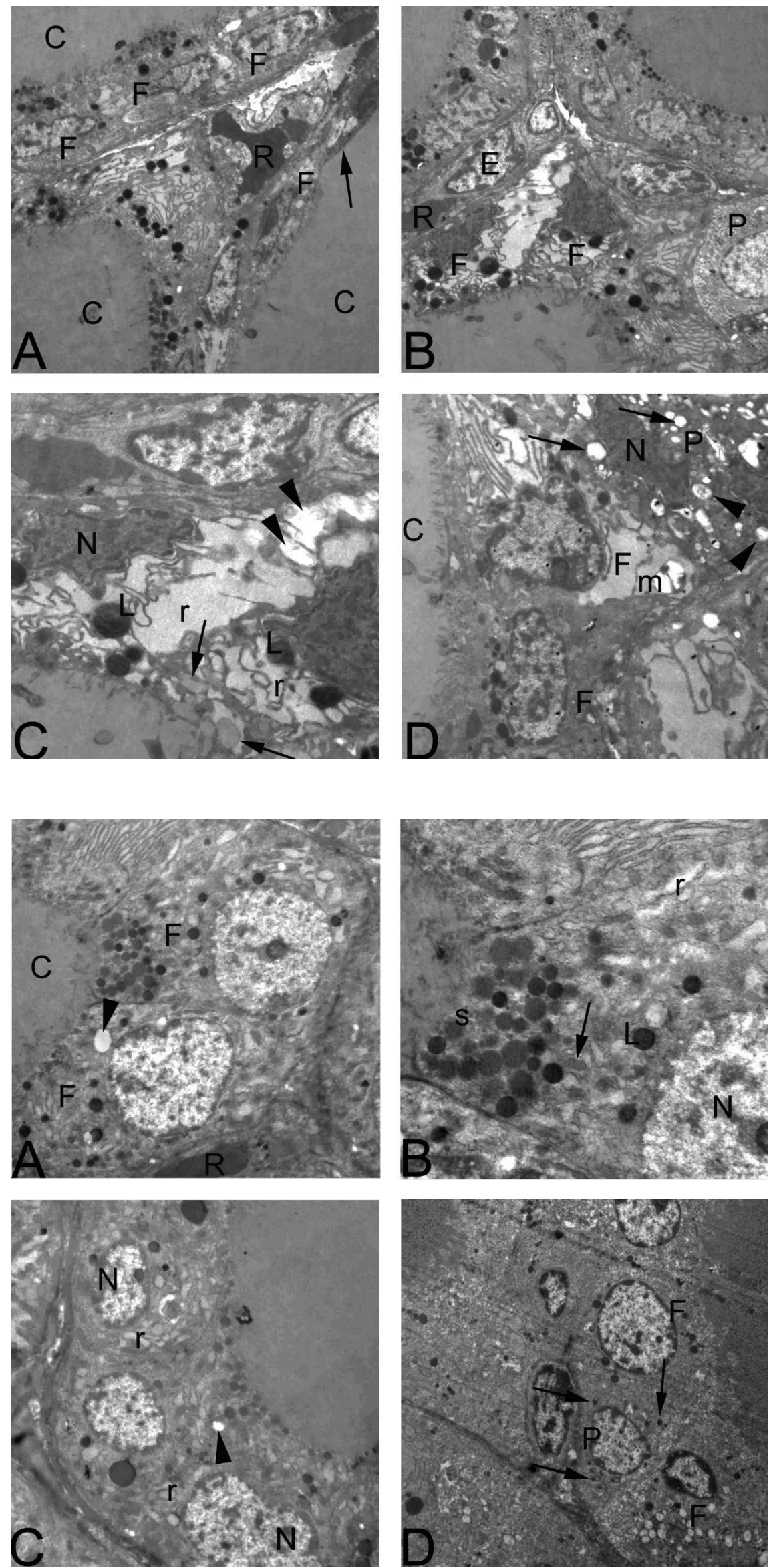

Figure 5. Electron micrographs of sections of the thyroid gland of group II showing; $\mathbf{A}$. Flattened follicular cells (F), blunt apical surface (arrow) and the follicular colloid (C). Blood capillaries with red blood cells (R) are seen between the follicles $(\times 1200)$, B. Follicular cells (F) with irregular dense shrunken nuclei and dilated endoplasmic reticulum. Endothelial cells $(E)$ of blood capillaries with red blood cells $(R)$ and $A$ parafollicular cell $(P)$ are seen $(\times 1200)$; C. A higher magnification displaying irregular dense shrunken nuclei (N), dilated endoplasmic reticulum (r), large intracellular vacuoles (arrow head), large colloid droplets (arrow) and multiple lysosomes (L) $(\times 2500)$; D. A parafollicular cell (P) with irregular shrunken nucleus $(\mathrm{N})$, multiple cytoplasmic vacuoles (arrow) and damaged mitochondria (arrow head). The follicular cells (F) with dilated endoplasmic reticulum and swollen damaged mitochondria $(\mathrm{m})$ and the colloid $(\mathrm{C})$ are seen $(\times 2000)$.

Figure 6. Electron micrographs of sections of the thyroid gland of group III showing; A. Nearly normal follicular cells $(F)$ with central spherical euchromatic nuclei, multiple lysosomes and some small vacuoles (arrow head). Red blood cell (R) is also seen $(\times 1500)$; $\mathbf{B}$. A higher magnification displaying the euchromatic nucleus (N), moderately dilated endoplasmic reticulum ( $r$ ), mitochondria (arrow), multiple secretory granules $(S)$ and lysosomes (L) $(\times 3000)$; C. Follicular cells having oval nuclei (N), moderately dilated endoplasmic reticulum $(r)$, and small vacuoles (arrow head) $(\times 1500)$; D. A parafollicular cell (P) having a near-normal euchromatic nucleus and its characteristic multiple cytoplasmic granules (arrow) ( $\times 1500) ; C$ - colloid. 
A

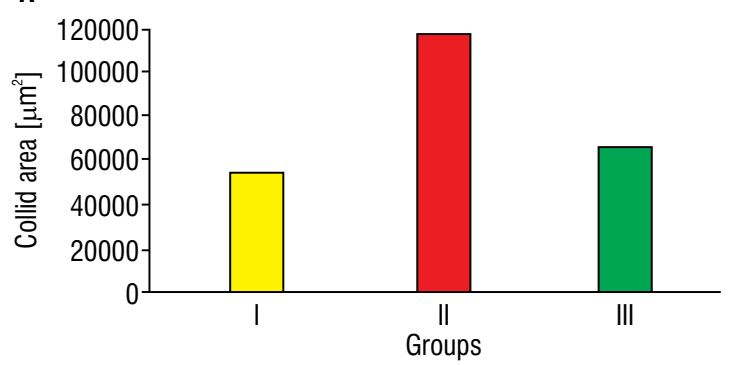

B

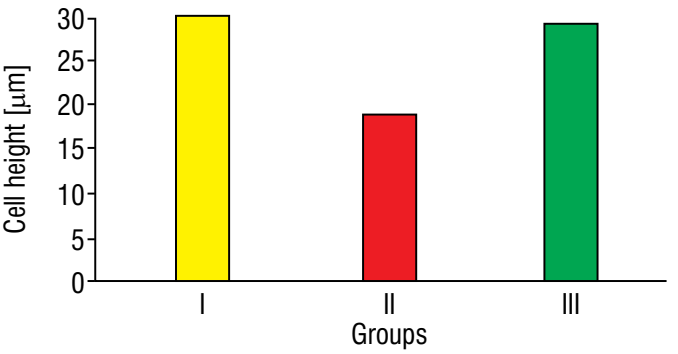

Figure 7. A histogram displaying; A. The colloid area of the thyroid follicles; B. The follicular cell height of the thyroid follicles in the different inspected groups.

Table 2. The colloid area and the follicular cell height of the thyroid follicles in the different studied groups

\begin{tabular}{lccc}
\hline & Group I & Group II & Group III \\
\hline Colloid area & $48094.2 \pm$ & $110583.9 \pm$ & $60246.64 \pm$ \\
{$\left[\mu \mathrm{m}^{2}\right]$} & \pm 1818.21 & $\pm 2040.96^{*}$ & $\pm 3087.09^{* *}$ \\
$\begin{array}{l}\text { Follicular cell } \\
\text { height }[\mu \mathrm{m}]\end{array}$ & $28.68 \pm 6.61$ & $17.6 \pm 3.45^{*}$ & $27.97 \pm 5.09^{* *}$ \\
\hline
\end{tabular}

Data were stated as mean \pm standard deviation, $\mathrm{P}$ value $=$ probability of chance, $p<0.05$ is significant; ${ }^{*}$ indicates a significant difference $\left({ }^{*} p<0.05\right.$ vs. group I, ${ }^{* *} p<0.005$ vs. group II, ANOVA test).

reticulum, large intracellular vacuoles, large colloid droplets and large pleomorphic lysosomes (Fig. 5B, C).

Some mitochondria appeared swollen with damaged cristae, could be seen close to the dilated endoplasmic reticulum of the follicular cells (Fig. 5D). Some parafollicular cells appeared normal, but others showed irregular shrunken nuclei with dense chromatin, multiple intracellular vacuoles and mitochondria with damaged cristae (Fig. 5D).

\section{Group III}

Thyroid follicular cells of (group III), exhibited a near-normal structure. They had spherical euchromatic nuclei and the cytoplasm contained moderately dilated endoplasmic reticulum, healthy mitochondria, apical microvilli, rounded lysosomes, ribosomes, and secretory granules but few small vacuoles could be seen (Fig. 6A, B).

Few follicular cells still had oval nuclei, moderately dilated endoplasmic reticulum and small vacuoles (Fig. 6C). The parafollicular cells of group III showed near-normal euchromatic nuclei with their characteristic multiple cytoplasmic granules (Fig. 6D).

\section{Morphometry}

Morphometric investigations revealed an extremely statistically significant increase in the colloid area in group II as compared to group I. Moreover, there was a statistically significant reduction of the colloid area in group III as compared to group II (Table 2, Fig. 7A).

Meanwhile, there was a marked statistically significant reduction of the follicular cell height in group II as compared to group I and a statistically significant increase of the follicular cell height in group III as compared to group II (Table 2, Fig. 7B).

\section{DISCUSSION}

Obese persons usually have hypertriglyceridemia [30]. Hypertriglyceridaemia induces the aggregation of neutral lipids in non-adipose tissues. The lipid aggregates in cells lead to a chronic state of cellular injury and malfunction called lipotoxicity [24]. Recently, lipotoxicity has been considered as a cause of many metabolic diseases and it seriously and extensively harms human health [3, 33].

In the present study, HFD feeding induced a state of obesity in rats of group II. The biochemical results revealed a state of hypothyroidism (high TSH and low free T3 and T4) with disordered lipid profile (high TC, TG, HDL and LDL). Moreover, examination of the semithin sections of rats fed with HFD (group II) revealed thyroid follicles exhibiting excessive amounts of colloid and markedly flattened follicular cells. The morphometric analysis also revealed a notably statistically significant elevation in the colloid area and a markedly statistically significant decrease of the follicular cell height in group II as compared to group I. These histo-morphological alterations of the thyroid gland in rats fed with HFD were similar to the changes seen in the thyroid gland of hypothyroid rats [25]. Our observations were compatible with the study of Shao et al., 2014 [41]. They observed flattened follicular cells and expanded follicles in the thyroid glands of rats fed with high fat-lard diet. They also noted markedly reduced levels of total thyroxine (TT4), free 


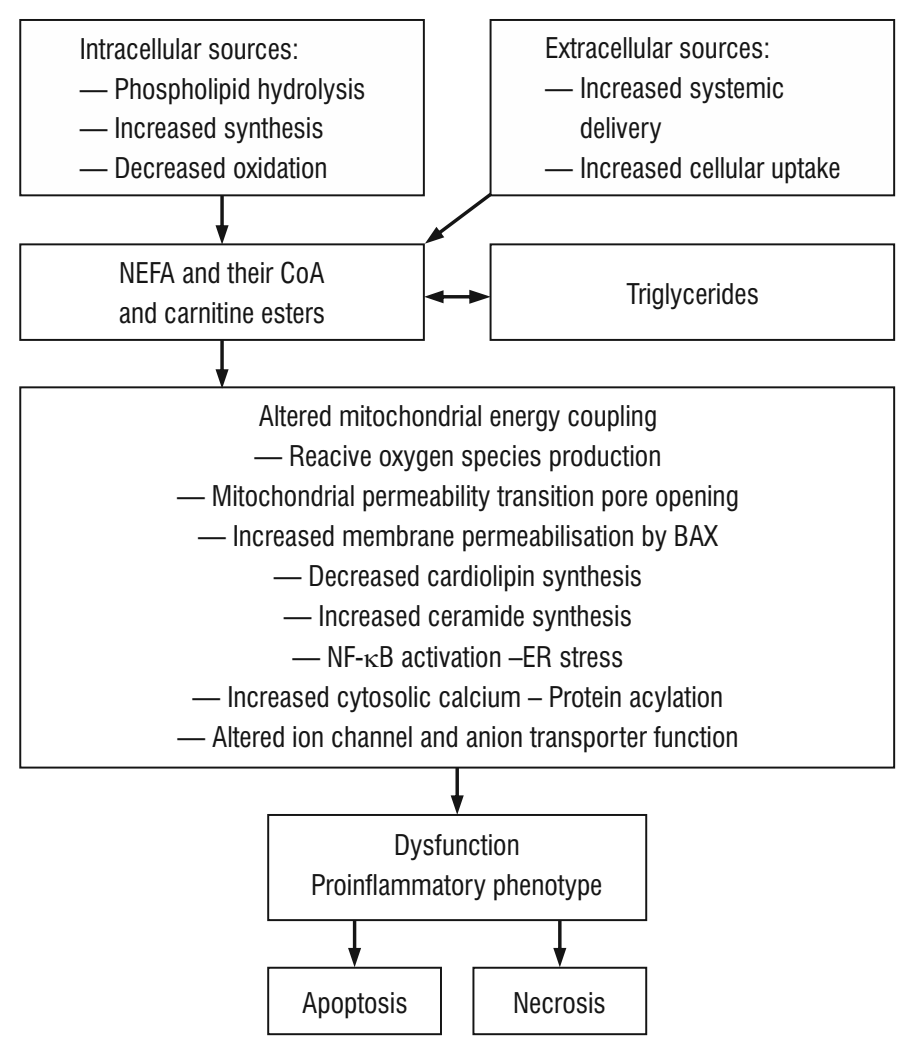

Figure 8. Illustrative diagram for cellular pathways of lipotoxicity (Quoted from Weinberg, 2006 [44]).

thyroxine (FT4) and increased levels of TSH in the rats' sera. Furthermore, Han et al., 2012 [20] observed a similar histo-morphological alteration in mice. They proved that HFD in addition to excess iodine has a more severely injurious effect on thyroid gland than excess iodine alone.

The aforementioned results in rats may be in harmony with the conclusions of Biondi, 2010 [6] in humans. He stated that one may assume an association between obesity, leptin increase, TSH increase, the changes in thyroid structure and morphology, and the occurrence of overt and subclinical hypothyroidism. The thyroid hormone deficiency in obese patients, particularly the subclinical pattern, may be undiagnosed. Subsequently, these obese patients will continue gaining weight and will have a disordered lipid profile, thus causing the obesity/thyroid correlation to a full circle.

Some follicular cells, in the semi-thin sections of group II, showed pyknotic nuclei and vacuolated cytoplasm. The cytoplasmic vacuolation and nuclear pyknosis are signs of cellular degeneration and necrosis and they may be a consequence of the lipotoxicity associated with obesity. In this context;
Engin, 2017 [15] stated that when packaging of high amounts of lipids into fat droplets fails, chronic elevation of fatty acids in blood will occur and may progress to noxious levels within non-adipose tissues. Weinberg, 2006 [44] added that the toxicity, in case of obesity, is derived mainly from NEFA (long-chain non-esterified fatty acids) and their products such as ceramides and diacylglycerols that accumulate due to the unsuccessful esterification and breakdown of the triglycerides [39]. Numerous pathways are included in the acute and chronic cellular effects of excess NEFA. They differ in their contributions from cell to cell (Fig. 8) [44].

Furthermore, the ultrathin sections of group II rats exhibited disordered cellular ultrastructure. Thyroid follicles showed blunt apical surface with absent microvilli, irregular shrunken nuclei with dense chromatin, an apparent decrease in the number of ribosomes and secretory granules and markedly dilated endoplasmic reticulum (Er). Large intracellular vacuoles, large colloid droplets, and pleomorphic lysosomes were also noticed, and some mitochondria appeared swollen with damaged cristae. Our observations were in harmony with that of Shao et al., 2014 [41]. They 
reported that HFD led to a reduced number of microvilli and secretory vesicles and wider perinuclear gaps. Cisternae of Er were dilated and near to the basal pole. Nuclei were twisted, and their chromatin was condensed.

In the cell, the Er is a fundamental organelle. It synthesizes the secretory proteins [17]. The ultrastructural dilatation in the Er always distinguishes " $\mathrm{Er}$ stress" [11, 18, 46]. Schröder and Kaufman, 2005 [40] stated that numerous environmental and genetic factors lead to "Er stress". In "Er stress", the dilatation occurred due to the aggregation of unfolded and misfolded proteins in the Er lumen. Growing evidence confirmed the engagement of "Er stress" in lipotoxicity induced by saturated long-chain fatty acids [9], and HFD prompted the enhancement of unfolded protein markers in the fatty tissue of rats [27]. So, the Er dilation may be associated with enhanced "Er stress" in thyrocytes induced by HFD feeding. In addition, the unfolding and misfolding of the proteins in the Er may be the cause of decreased serum TT4 and FT4 concentrations in HFD feeding.

Interestingly, in the present study, some parafollicular cells in sections of group II rats, also exhibited pyknotic nuclei by light microscope. By electron microscope, these cells showed irregular shrunken nuclei with dense chromatin, multiple intracellular vacuoles, and mitochondria with damaged cristae. All these changes were reversed in group III. Zienab et al., 2013 [49] assumed a mutual interdependence between the follicular and parafollicular cells. So, thyroid gland disruptors affecting follicular cells could also affect the parafollicular cells due to the cellular interdependence. Similarly, Dadan et al., 2003 [12] hypothesized that the possible mechanisms involved in the parafollicular cells changes were in line with changes of follicular cells and increased TSH level in hypothyroid rats. Martín-Lacave et al., 2009 [32] reported that parafollicular cells are principally known for synthesizing calcitonin, a hypo-calcaemic hormone. Additionally, parafollicular cells may be included in the intrathyroidal regulation of follicular cells, proposing a possible inter-relationship between the two cell types. If this assumption is true, massive alterations induced by various factors in the follicular cells may also influence the parafollicular cells.

In the present study, mast cells infiltration appeared in group II in between the follicles and in the loose connective tissue surrounding the thyroid gland. This finding was repealed in group III. Żelechowska et al., 2018 [48] reported that multiple immune cell populations contribute to obesity patho-mechanisms and the induction of chronic inflammation. Mast cells number particularly increases in obese individuals. They secrete strong pro-inflammatory mediators, chemokines, and cytokines. Mast cells number is higher in adipose tissue of obese patients than that of lean individuals. Mast cells may take part in tissue inflammation by the production of interferon gamma and interleukin-6 [42]. Moreover, mast cells number is related to fibrosis, macrophage inflammation and endothelial activation of adipose tissue in obesity [13]. The aforementioned studies ensure that mast cell populations increased in adipose tissue of obese patients and mast cells secrete many substances that produce a state of tissue inflammation. Moreover, the present study ensured that the mast cells apparently increased in between the follicles and in the soft tissue around the thyroid gland. So, it could be assumed that mast cells, by their secretions, may also play a role in thyroid gland structural and functional alterations in obesity.

In the current study, vacuolisation of the colloid within the thyroid follicles was seen in the semithin sections of group II. Wang et al., 2009 [43] depicted that extensive vacuolisation of colloid in some follicles was due to increased endocytotic activity of the thyroid gland to release the stored hormones to compensate T3 and T4 deficiency. They hypothesized that this vacuolisation is due to increased serum (TSH).

In the present study, examination of semithin sections of rats fed with HFD and treated with metformin (group III) showed a nearly normal follicular structure. The morphometric analysis also revealed a statistically significant reduction of the colloid area and an increase of the follicular cell height in group III as compared to group II. Moreover, the ultrastructure of follicular cells exhibited rounded euchromatic nuclei and the cytoplasm contained moderately dilated $\mathrm{Er}$, healthy mitochondria, apical microvilli, rounded lysosomes, ribosomes, and secretory granules but few small vacuoles could be seen. The lipid profile, serum TSH and thyroid hormones levels were also improved. The aforementioned observations pointed for the ameliorative effect of metformin on thyroid structure and function. Hu et al., 2017 [22] reported that rodents on metformin treatment manifested relatively lower body weight and symptoms like diarrhoea and irritability with a notable elevation in FT3 and FT4. Serum TSH level was also significantly decreased. 
The previous data clarify that metformin can alter thyroid function and induce a state of hyperthyroidism. Karimifar et al., 2014 [26] added that metformin could produce a 'buffer effect' on TSH level in blood. Thyroid stimulating hormone returned to the middle of its normal range upon metformin administration. Moreover, Krysiak and Okopien, 2011 [29] suggested that metformin may change the activity of hypothalamic-pituitary-thyroid axis at the peripheral tissues level by its direct influence on the thyroid gland itself.

Additionally, Anil et al., 2016 [4] stated that metformin treatment significantly diminished thyroid volume and nodule size by ultrasonography. Ittermann et al., 2013 [23] also reported that patients with diabetes mellitus tended to have a significantly increased thyroid volume and a greater frequency of incident goitre and nodules. Besides, diabetic patients on metformin therapy had a relatively reduced thyroid volume with a lower risk for development of thyroid nodules. The aforementioned studies demonstrated that metformin may have a TSH-lowering effect and could increase thyroid hormone secretion by the thyroid gland. The current study added that metformin had also an ameliorative effect on the thyroid gland structure. In other words, metformin may correct the structural and functional changes that occur in thyroid gland in obesity. However, more associated studies are necessary to analyse the pathophysiological basis of metformin action in thyroid gland of obese patients.

\section{CONCLUSIONS}

Obesity induced by HFD in female rats provoked deleterious structural and functional changes in the thyroid gland, particularly at the ultrastructural level. These changes were ameliorated by metformin therapy. Further studies are needed to clarify the underlying mechanisms of metformin action on the thyroid gland in obese female rats.

\section{Ethics approval and consent to participate}

All the procedures of the experiment were carried out according to the guide rules of the Committee of the Animal Research Ethics (CARE), Faculty of Medicine, Ain Shams University.

\section{REFERENCES}

1. Acikel Elmas M, Enes Cakıcı S, Rahmi Dur I, et al. Protective effects of exercise on heart and aorta in high-fat diet-induced obese rats. Tissue Cell. 2019; 57:
57-65, doi: 10.1016/j.tice.2019.01.005, indexed in Pubmed: 30947964.

2. Ajjan RA, Watson PF, Findlay $C$, et al. The sodium iodide symporter gene and its regulation by cytokines found in autoimmunity. J Endocrinol. 1998; 158(3): 351-358, doi: 10.1677/joe.0.1580351, indexed in Pubmed: 9846164.

3. Alarcón-Vila C, Fabriàs G, Martínez L, et al. Myristic acid potentiates palmitic acid-induced lipotoxicity and steatohepatitis associated with lipodystrophy by sustaning de novo ceramide synthesis. Oncotarget. 2015; 6(39): 41479-41496, doi: 10.18632/oncotarget.6286, indexed in Pubmed: 26539645.

4. Anil C, Kut A, Atesagaoglu B, et al. Metformin decreases thyroid volume and nodule size in subjects with insulin resistance: a preliminary study. Med Princ Pract. 2016; 25(3): 233-236, doi: 10.1159/000442821, indexed in Pubmed: 26618447.

5. Apovian CM, Aronne $\mathrm{U}$, Bessesen DH, et al. Pharmacological management of obesity: an endocrine Society clinical practice guideline. J Clin Endocrinol Metab. 2015; 100(2): 342-362, doi: 10.1210/jc.2014-3415, indexed in Pubmed: 25590212.

6. Biondi B. Thyroid and obesity: an intriguing relationship. J Clin Endocrinol Metab. 2010; 95(8): 3614-3617, doi: 10.1210/jc.2010-1245, indexed in Pubmed: 20685890.

7. Buettner R, Schölmerich J, Bollheimer LC. High-fat diets: modeling the metabolic disorders of human obesity in rodents. Obesity (Silver Spring). 2007; 15(4): 798-808, doi: 10.1038/oby.2007.608, indexed in Pubmed: 17426312.

8. Camastra S, Manco M, Frascerra S, et al. Daylong pituitary hormones in morbid obesity: effects of bariatric surgery. Int J Obes (Lond). 2009; 33(1): 166-172, doi: 10.1038/ ijo.2008.226, indexed in Pubmed: 19050673.

9. Cao J, Dai DL, Yao L, et al. Saturated fatty acid induction of endoplasmic reticulum stress and apoptosis in human liver cells via the PERK/ATF4/CHOP signaling pathway. Mol Cell Biochem. 2012; 364(1-2): 115-129, doi: 10.1007/s11010011-1211-9, indexed in Pubmed: 22246806.

10. Chamberlain JJ, Herman WH, Leal S, et al. Pharmacologic therapy for type 2 diabetes: synopsis of the 2017 American Diabetes Association standards of medical care in diabetes. Ann Intern Med. 2017; 166(8): 572-578, doi: 10.7326/ M16-2937, indexed in Pubmed: 28288484.

11. Chow SE, Kao CH, Liu YT, et al. Resveratrol induced ER expansion and ER caspase-mediated apoptosis in human nasopharyngeal carcinoma cells. Apoptosis. 2014; 19(3): 527-541, doi: 10.1007/s10495-013-0945-0, indexed in Pubmed: 24264887.

12. Dadan J, Zbucki R Rt, Sawicki B, et al. Activity of the thyroid parafollicular (C) cells in simple and hyperactive nodular goitre treated surgically - preliminary investigations. Folia Morphol. 2003; 62(4): 443-445, indexed in Pubmed: 14655137.

13. Divoux A, Moutel S, Poitou C, et al. Mast cells in human adipose tissue: link with morbid obesity, inflammatory status, and diabetes. J Clin Endocrinol Metab. 2012; 97(9): E1677-E1685, doi: 10.1210/jc.2012-1532, indexed in Pubmed: 22745246.

14. Dowling R, Goodwin PJ, Stambolic V. Understanding the benefit of metformin use in cancer treatment. BMC Med. 
2011; 6(9): 33, doi: 10.1186/1741-7015-9-33, indexed in Pubmed: 21470407.

15. Engin AB. What is lipotoxicity? Adv Exp Med Biol. 2017; 960: 197-220, doi: 10.1007/978-3-319-48382-5_8, indexed in Pubmed: 28585200.

16. Fournier JP, Yin $\mathrm{H}, \mathrm{Yu} \mathrm{OH}$, et al. Metformin and low levels of thyroid-stimulating hormone in patients with type 2 diabetes mellitus. CMAJ. 2014; 186(15): 1138-1145, doi: 10.1503/cmaj.140688, indexed in Pubmed: 25246411.

17. Gething MJ, Sambrook J. Protein folding in the cell. Nature. 1992; 355(6355): 33-45, doi: 10.1038/355033a0, indexed in Pubmed: 1731198.

18. Goldshmidt H, Matas D, Kabi A, et al. Persistent ER Stress Induces the Spliced Leader RNA Silencing Pathway (SLS), Leading to Programmed Cell Death in Trypanosoma brucei. PLoS Pathogens. 2010; 6(1): e1000731, doi: 10.1371/ journal.ppat.1000731.

19. Graziano MP, Sybertz EJ, Strader CD, et al. Diet-induced obese mice develop peripheral, but not central, resistance to leptin. J Clin Invest. 1997; 99(3): 385-390, doi: 10.1172/jci119171.

20. Han H, Xin P, Zhao L, et al. Excess iodine and high-fat diet combination modulates lipid profile, thyroid hormone, and hepatic LDLr expression values in mice. Biol Trace Elem Res. 2012; 147(1-3): 233-239, doi: 10.1007/s12011-0119300-x, indexed in Pubmed: 22222482.

21. Hong $Y H$, Jung $E Y$, Park $Y$, et al. Enzymatic improvement in the polyphenol extractability and antioxidant activity of green tea extracts. Biosci Biotechnol Biochem. 2013; 77(1): 22-29, doi: 10.1271/bbb.120373, indexed in Pubmed: 23291774.

22. Hu X, Liu Y, Wang $C$, et al. Metformin affects thyroid function in male rats. Oncotarget. 2017; 8(64): 107589-107595, doi: 10.18632/oncotarget.22536, indexed in Pubmed: 29296189.

23. Ittermann T, Markus MRP, Schipf $S$, et al. Metformin inhibits goitrogenous effects of type 2 diabetes. Eur J Endocrinol. 2013; 169(1): 9-15, doi: 10.1530/EJE-130101, indexed in Pubmed: 23572084.

24. Jorde U, Chokshi A, Drosatos K, et al. Ventricular assist device implantation corrects myocardial lipotoxicity, reverses insulin resistance, and normalizes cardiac metabolism in patients with advanced heart failure. Circulation. 2012; 125(23): 2844-2853, doi: 10.1161/CIRCULATIONAHA.111.060889, indexed in Pubmed: 22586279.

25. Karawya F, Zahran N, Azzam E. Is water fluoridation a hidden cause of obesity? Histological study on thyroid follicular cells of albino rats. Egypt J Histol. 2015; 38(3): 547-557, doi: 10.1097/01.ehx.0000470830.83093.88.

26. Karimifar M, Aminorroaya A, Amini M, et al. ffect of metformin on thyroid stimulating hormone and thyroid volume in patients with prediabetes: A randomized placebo-controlled clinical trial. J Res Med Sci. 2014; 19(11): 1019-1026, indexed in Pubmed: 25657744.

27. Kawasaki N, Asada R, Saito A, et al. Obesity-induced endoplasmic reticulum stress causes chronic inflammation in adipose tissue. Sci Rep. 2012; 2: 799, doi: 10.1038/ srep00799, indexed in Pubmed: 23150771.

28. Kronenberg H, Melmed S, Kenneth SP. Williams Textbook of Endocrinology. Acta Endocrinologica (Bucharest) Sauners, Elsevier Inc. 2007, doi: 10.4183/aeb.2016.113.
29. Krysiak R, Okopien B. Thyrotropin-lowering effect of metformin in a patient with resistance to thyroid hormone. Clin Endocrinol (Oxf). 2011; 75(3): 404-406, doi: 10.1111/j.13652265.2011.04058.x, indexed in Pubmed: 21521326.

30. Pejic RN, Lee DT. Hypertriglyceridemia. J Am Board Fam Med. 2006; 19(3): 310-316, doi: 10.3122/jabfm.19.3.310.

31. Liu G, Liang L, Bray GA, et al. Thyroid hormones and changes in body weight and metabolic parameters in response to weight loss diets: the POUNDS LOST trial. Int J Obes (Lond). 2017; 41(6): 878-886, doi: 10.1038/ijo.2017.28, indexed in Pubmed: 28138133.

32. Martín-Lacave I, Borrero MJ, Utrilla JC, et al. C cells evolve at the same rhythm as follicular cells when thyroidal status changes in rats. J Anat. 2009; 214(3): 301-309, doi: 10.1111/j.1469-7580.2008.01044.x, indexed in Pubmed: 19245497.

33. Moorhead JL, Chen Y, Ma KZ, et al. Inflammatory stress exacerbates lipid accumulation in hepatic cells and fatty livers of apolipoprotein E knockout mice. Hepatology. 2008; 48(3): 770-781, doi: 10.1002/hep.22423, indexed in Pubmed: 18752326.

34. Nauck M, Warnick G, Rifai N. Methods for measurement of Idl-cholesterol: a critical assessment of direct measurement by homogeneous assays versus calculation. Clin Chem. 2002; 48(2): 236-254, doi: 10.1093/ clinchem/48.2.236.

35. Neves JS, Oliveira SC, Pedro J, et al. Effect of metformin on TSH levels in patients with morbid obesity and diabetes mellitus. Revista Portuguesa de Diabetes. 2017; 12(4): 143-148.

36. Oberley CC, Gourronc F, Hakimi S, et al. Murine epidermal side population possesses unique angiogenic properties. Exp Cell Res. 2008; 314(4): 720-728, doi: 10.1016/j.yexcr.2007.11.002, indexed in Pubmed: 18067890.

37. Pekary AE, Hershman JM. Tumor necrosis factor, ceramide, transforming growth factor-beta1, and aging reduce $\mathrm{Na}+/ \mathrm{l}$ - symporter messenger ribonucleic acid levels in FRTL-5 cells. Endocrinology. 1998; 139(2): 703-712, doi: 10.1210/endo.139.2.5760, indexed in Pubmed: 9449644.

38. Shaker SM, Magdy Y, Abd-Elaziz L, et al. Histological study on the effect of metformin on high-fat-diet-induced liver injury in adult male albino rats. Egypt J Histol. 2014; 37(3): 592-602, doi: 10.1097/01.ehx.0000452726.54766.93.

39. Schaffer JE. Lipotoxicity: when tissues overeat. Curr Opin Lipidol. 2003; 14(3): 281-287, doi: 10.1097/00041433200306000-00008, indexed in Pubmed: 12840659.

40. Schröder M, Kaufman RJ. ER stress and the unfolded protein response. Mutat Res. 2005; 569(1-2): 29-63, doi: 10.1016/j.mrfmmm.2004.06.056, indexed in Pubmed: 15603751.

41. Shao Ss, Zhao Yf, Song Yf, et al. Dietary high-fat lard intake induces thyroid dysfunction and abnormal morphology in rats. Acta Pharmacol Sin. 2014; 35(11): 1411-1420, doi: 10.1038/aps.2014.82, indexed in Pubmed: 25263336.

42. Stienstra R, van Diepen JA, Tack CJ, et al. Inflammasome is a central player in the induction of obesity and insulin resistance. Proc Natl Acad Sci U S A. 2011; 108(37): 15324-15329, doi: 10.1073/pnas.1100255108, indexed in Pubmed: 21876127. 
43. Wang H, Yang Z, Zhou B, et al. Fluoride-induced thyroid dysfunction in rats: roles of dietary protein and calcium level. Toxicol Ind Health. 2009; 25(1): 49-57, doi: 10.1177/0748233709102720, indexed in Pubmed: 19318504

44. Weinberg JM. Lipotoxicity. Kidney Int. 2006; 70(9): 1560-1566, doi: 10.1038/sj.ki.5001834, indexed in Pubmed: 16955100.

45. Winter WE, Signorion MR. Review: molecular thyroidology. Ann Clin Lab Sci. 2001; 31(3): 221-244, indexed in Pubmed: 11508826.

46. Xu YY, You YW, Ren XH, et al. Endoplasmic reticulum stress-mediated signaling pathway of gastric cancer apoptosis. Hepatogastroenterology. 2012; 59(120): 2377-2384, doi: 10.5754/hge12369, indexed in Pubmed: 22688017.
47. Yan Wj, Mu Y, Yu N, et al. Protective effects of metformin on reproductive function in obese male rats induced by high-fat diet. J Assist Reprod Genet. 2015; 32(7): 1097-1104, doi: 10.1007/s10815-015-0506-2, indexed in Pubmed: 26081124.

48. Żelechowska P, Agier J, Kozłowska E, et al. Mast cells participate in chronic low-grade inflammation within adipose tissue. Obes Rev. 2018; 19(5): 686-697, doi: 10.1111/ obr.12670, indexed in Pubmed: 29334696.

49. Zienab AG, Ismail M, Askar E, et al. The collateral damage of sodium nitrates and alleviating properties of vitamin $C$ on thyroid gland of adult male albino rats: toxicological, histological and ultrastructural study. Ain Shams J Forensic Med Clin Toxicol. 2013; 21(2): 98-110, doi: 10.21608/ ajfm.2013.19376. 